Fernando Farano Stacchini

\title{
PROTEÇÃO DE CULTIVARES E OS EFEITOS DAS PATENTES DE INVENÇÕES BIOTECNOLÓGICAS NO BRASIL
}

\author{
Dissertação de Mestrado \\ Orientador: Professor Doutor Balmes Vega Garcia
}

Universidade de São Paulo

Faculdade de Direito

São Paulo-SP

2019 
Fernando Farano Stacchini

\section{PROTEÇÃO DE CULTIVARES E OS EFEITOS DAS PATENTES DE INVENÇÕES BIOTECNOLÓGICAS NO BRASIL}

Dissertação de mestrado apresentada à banca examinadora do Programa de Pósgraduação em direito, da Faculdade de Direito da Universidade de São Paulo, na área de concentração Direito Comercial, sob a orientação do Professor Balmes Vega Garcia.

Universidade de São Paulo

Faculdade de Direito

São Paulo-SP

2019 
S775p Stacchini, Fernando Farano

PROTEÇÃO DE CULTIVARES E OS EFEITOS DAS PATENTES DE INVENÇÕES

BIOTECNOLÓGICAS NO BRASIL / Fernando Farano

Stacchini; orientador Balmes Veiga Garcia. -- Ribeirão Preto, 2019. 112 p.

Dissertação (Mestrado - Departamento de Direito Comercial) -- Faculdade de Direito, Universidade de São Paulo, 2019.

1. . I. Garcia, Balmes Veiga, orient. II. Título 


\section{RESUMO}

O propósito deste estudo é analisar a proteção ao desenvolvimento de novas cultivares no Brasil pelo sistema específico da Lei $\mathrm{n}^{0}$ 9.456/97 e respectiva regulamentação ("Lei de Proteção de Cultivares" ou "LPC"), abordando se e em que medida as patentes relacionadas a produtos e processos biotecnológicos que resultem em novas variedades de plantas ou que sejam utilizados no desenvolvimento de novas variedades vegetais podem caracterizar uma proteção, ainda que indireta, das novas cultivares pelo sistema de patentes. Para tanto, dividiu-se esse estudo em quatro partes, sendo que na primeira parte, analisar-se-á o desenvolvimento histórico do sistema de patentes no que tange às invenções biotecnológicas, com o intuito de identificar o desenvolvimento de novas cultivares como tipo específico objeto do sistema de patentes. Na segunda parte, tratar-se-á de identificar os limites da proteção normativa das invenções biotecnológicas e das novas variedades vegetais, de acordo com os tratados internacionais que regulam a matéria, bem como de acordo com a legislação brasileira, especialmente a Lei $n^{\circ}$ 9.279/96 ("Lei de Propriedade Industrial" ou "LPI"). Na terceira parte será analisada a doutrina especializada para, com embasamento em referida doutrina, enfrentar as questões relativas ao tema propostas a seguir, para a comprovação ou afastamento da hipótese de que patentes de invenção biotecnológica podem implicar uma dupla proteção para novas variedades vegetais. Por fim, na quarta parte serão analisados os processos judiciais mais relevantes envolvendo conflitos atinentes à proteção de novas cultivares e patentes de invenções biotecnológicas para que se possa cotejar as conclusões da parte 3 com os entendimentos jurisprudenciais. Espera-se, com este trabalho, concluir, por meio de análise dogmático-normativa e jurisprudencial, se há ou não proteção indireta das novas variedades vegetais sob o sistema de patentes e, dessa forma, contribuir para a solução de eventuais problemas jurídicos advindos da interface do sistema de patentes e do sistema específico de proteção de cultivares sob o marco regulatório brasileiro atual.

Palavras-chave: Propriedade Industrial, Patentes de Invenções Biotecnológicas, Lei de Proteção de Cultivares, Dupla Proteção 


\section{ABSTRACT}

The purpose of this study is to analyze the protection of plant varieties development in Brazil, according to the system provided for by Law $\mathrm{N}^{\circ}$ 9.456/97 and its regulations ("Plant Varieties Protection Law"), taking into specific consideration if - and to what extent - the patents related to the biotechnological products and processes that result or are used in the development of new plant varieties could imply indirect protection to plant varieties by the patent system under Brazilian laws. For such purpose, this study is divided in four sections. The first section shall analyze the historical development of the patent system with regard to biotechnological inventions, in order to identify the development of new plant varieties as a specific object of the patent system. The second part shall be dedicated to identifying the limits of the normative protection of biotechnological inventions and of new plant varieties under the international treaties that regulate this subject matter and under Brazilian laws. The third section shall be dedicated to the analysis of the specialized doctrine, based on which the questions related to the problem specified below shall be answered to validate or invalidate the initial hypothesis that patents for biotechnological inventions may imply a double protection for plant varieties. Finally, the fourth section will be employed to discuss the most relevant judicial cases involving controversies related to plant varieties protection and patents of biotechnological inventions, with the purpose of a comparison between the conclusions of section 3 and the relevant court decisions of the courts. The intention with this work is to confirm, through dogmatic-normative and jurisprudential analysis, whether there is indirect protection of the new plant varieties through the patent system, and, in this way, contribute to the solution of possible legal controversies regarding the interface of the patent system and the specific system of protection of plant varieties under Brazilian current regulatory framework.

Key-words: Industrial Property; Biotechnological Inventions Patents; Plant Varieties; Cultivars Law; Double Protection. 


\section{AGRADECIMENTOS}

Aos meus pais, Aldo e Rosa Maria, pelo exemplo de vida, pelos princípios, pelo amor e pelo apoio incondicional, sempre.

Aos meus filhos, Rodrigo, Sofia e Isabela que me ensinam diariamente que a diversidade, a coragem e a bondade são essenciais para a humanidade.

Ao Dr. Eli Loria, por ter inspirado e instigado o desafio de voltar à velha academia e pelo exemplo intelectual.

Às minhas colegas de profissão Dras. Vanessa Corsetti Gonçalves Teixeira, Ana Carolina D'Atri, Mariana Caparelli e Paola Lorenzetti, pela inestimável ajuda em apresentar material de pesquisa, debater argumentos e revisar meus textos.

Aos Profs. Newton Silveira e Balmes Vega Garcia pela confiança, paciência e apoio na realização desta jornada acadêmica. 


\section{DEDICATÓRIA}

À minha esposa Renata Ciampi, pelo amor e bondade com que se dedicou a me incentivar a realizar este trabalho e por me ajudar a superar os momentos de dúvida e incerteza com exemplos de perseverança. 


\section{Sumário}

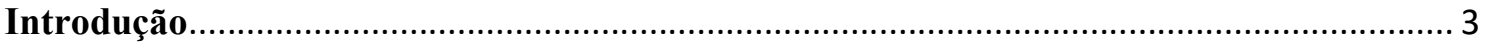

Relevância do tema ............................................................................................. 4

Capítulo 1: Proteção da Biotecnologia e das Cultivares - Notícia Histórica ..................... 7

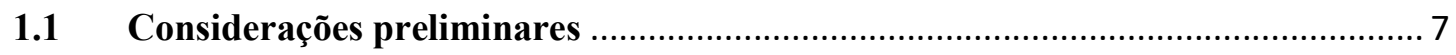

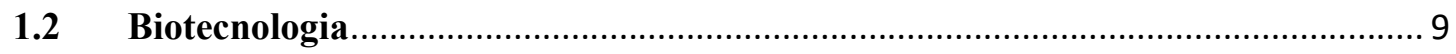

1.3 O uso científico e comercial de seres vivos e material biológico e as preocupações ético-morais para manipulação e exploração comercial de invenções biotecnológicas e desenvolvimentos vegetais.

1.4 Os Direitos de propriedade intelectual de novas variedades vegetais no âmbito

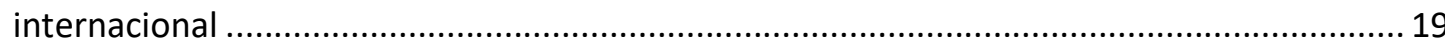

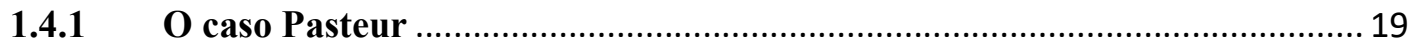

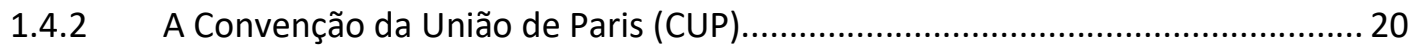

1.4.3 A Proteção de variedades vegetais nos Estados Unidos ................................. 24

1.5 As preocupações que levaram à criação da UPOV e ao regime específico de proteção de cultivares.

Capítulo 2: Proteção de invenções biotecnológicas e de cultivares - Aspectos Normativos Atuais 30

2.1. Normatividade Internacional sobre Patentes sobre invenções biotecnológicas... 30

2.1.1. TRIPS: aspectos relevantes …........................................................ 31

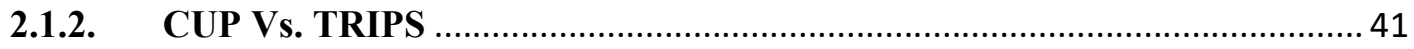

2.1.3. UPOV: A evolução do regime específico: as atas de 1978 e $1991 \ldots \ldots \ldots \ldots \ldots . . . . . .42$

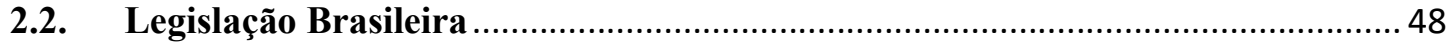

2.2.1. Antecedentes normativos: Constituições e legislação específica ................. 48

2.2.2. Sistema Constitucional atual ....................................................... 51

2.2.3. Proteção de invenções biotecnológicas pelo sistema de patente brasileiro (Lei

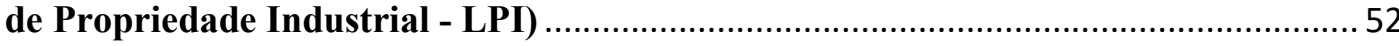

2.2.4. Proteção sui generis de cultivares na legislação brasileira ........................ 60

2.2.5. A questão da dupla proteção do ponto de vista normativo: há de fato uma

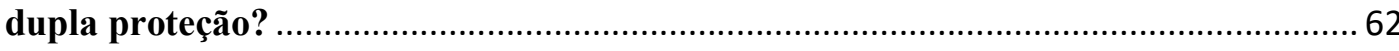

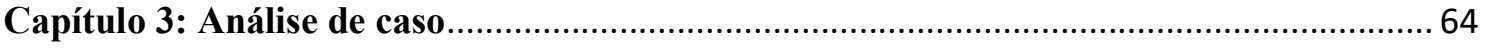

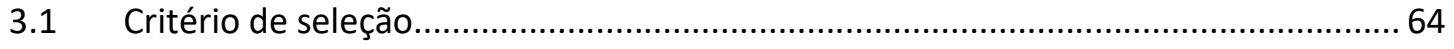

O Caso Monsanto ..................................................................................... 67

Considerações sobre o Caso Monsanto ........................................................... 77

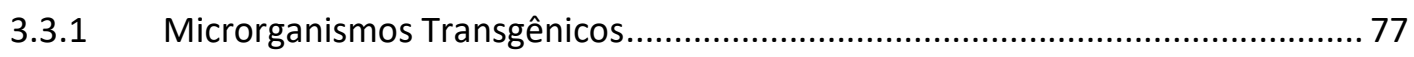

3.3.2 Bens jurídicos protegidos sob a Lei de Propriedade Industrial e sob a Lei de Proteção de Cultivares. 79 


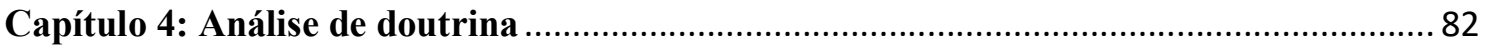

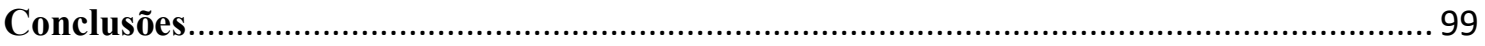

Impactos e consequências das conclusões preliminares ........................................................ 99

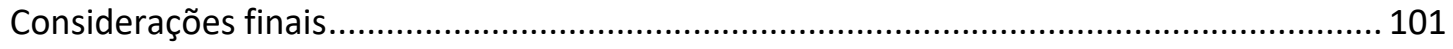

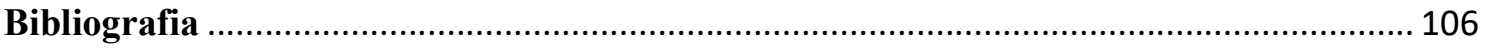




\section{Introdução}

Este estudo pretende analisar a proteção ao desenvolvimento de novas cultivares no Brasil pelo sistema específico da Lei de Proteção de Cultivares ${ }^{1}$, abordando se e em que medida as patentes relacionadas a produtos e processos biotecnológicos que resultem ou que sejam utilizados no desenvolvimento de novas variedades vegetais podem caracterizar uma proteção, ainda que indireta, das novas cultivares pelo sistema de patentes.

Neste sentido, para o propósito de introduzir o tema, necessário se faz colocar que não serão tratados todos os aspectos do sistema de patentes no tocante a invenções biotecnológicas. O sistema de patentes será analisado apenas conforme necessário para verificar quando e por que se julgou relevante desenvolver um sistema específico para a proteção das criações de novas variedades vegetais. Dessa forma, analisar em que grau coexistem harmonicamente as legislações pertinentes a patentes de invenções biotecnológicas e a proteção de novas cultivares em vigor no Brasil é pertinente e relevante para as questões que serão apresentadas no Capítulo 2 deste estudo e confrontadas com a jurisprudência e a doutrina abordadas nos Capítulos 3 e 4 , conforme mostraremos nesta introdução. Ademais, trataremos das questões referentes ao sistema de patentes quando for relevante analisar como e de que maneira, quando aplicado para invenções biotecnológicas, esse sistema dialoga com o de proteção de novas variedades vegetais. Isso porque, dada a extensão do tema da biotecnologia, sua análise poderia inviabilizar a abordagem, nesse trabalho, dos detalhes do tema que se quer tratar. Faz-se, ademais, abundante a literatura especializada sobre o sistema de patentes em biotecnologia, de forma que não se incorre em erro ao limitar sua abordagem neste trabalho ${ }^{2}$.

Não será realizada, ademais, nesta pesquisa, uma abordagem de direito comparado em sentido estrito, já que não se realizará uma análise detida dos institutos estrangeiros,

\footnotetext{
${ }^{1}$ Lei N ${ }^{\circ} 9.456$ de 25 de abril de 1997.

${ }^{2}$ Para citar apenas as obras e autores mais recentes que cuidaram de forma exaustiva da questão, vale lembrar: DEL NERO, Patícia Aurélia, Propriedade Intelectual: A tutela jurídica da biotecnologia, 2. ed. São Paulo: Revista dos Tribunais, 2004. FERRERO ZOCCOLATO, Graziela, FREITAS, Rogério Edvaldo, Propriedade Intelectual e Aspectos Regulatórios em Biotecnologia, Brasília: IPEA, 2013. CASABONA, Carlos María Romeo; QUEIROZ, Juliane Fernandes (Coord.). Biotecnologia e suas implicações éticojurídicas. Belo Horizonte: Del Rey, 2004. IACOMINI, Vanessa, Propriedade intelectual e biotecnologia, Curitiba: Juruá Editora, 2009.
} 
somente lançando-se mão dos mesmos na medida em que isso for pertinente para analisar ou interpretar o sistema brasileiro para a proteção de novas variedades vegetais. Dessa forma, vale esclarecer que os exemplos estrangeiros analisados aqui serão selecionados em função de sua relevância para a evolução histórica da proteção de novas cultivares e/ou pela influência que tenham tido no desenvolvimento da legislação, doutrina ou jurisprudência brasileira sobre a matéria.

\section{Relevância do tema}

De acordo com dados da Organização para a Cooperação e Desenvolvimento Econômico (OCDE), o setor da agricultura brasileira mais do que dobrou desde 1990, tendo a indústria da agricultura produzido 7.868,8 mil toneladas em 2014. Para a OCDE, nos próximos 10 anos, o Brasil deve se tornar um dos maiores fornecedores da demanda global por produtos alimentícios. Os resultados das projeções de grãos (Arroz, Feijão, Milho, Soja e Trigo) mostram que, em 2016/2017, o Brasil terá uma produção de 148 milhões de toneladas, superior em 27\% em relação a 2005/2006. Trigo, soja e milho lideram o aumento de produção em termos relativos.

Nesse contexto, a agricultura pode ser indicada como um dos setores mais relevantes da economia brasileira e, portanto, a proteção das variedades vegetais é uma questão de considerável relevância para fomentar a inovação nesse setor.

Ao mesmo tempo em que é importante proteger o desenvolvimento de novas variedades vegetais, garantindo a proteção daqueles que investem em pesquisa e inovação, é importante analisar como essa proteção pode impactar os produtores rurais, a produção de alimentos e o desenvolvimento econômico e social do Brasil. Já aqui é importante notar que há preocupações distintas no tocante à proteção dos investimentos em pesquisa e desenvolvimento e no tocante à proteção do interesse público no que diz respeito a desenvolvimento econômico, social, segurança alimentar e preservação da biodiversidade e do meio-ambiente.

Como já mencionado, a possibilidade de dupla proteção gera insegurança e pode resultar em um conflito entre as limitações aos direitos de exclusividade determinadas 
pelo sistema de patentes e pelo sistema especificado nas convenções realizadas pela União Internacional para Proteção das Obtenções Vegetais (UPOV). ${ }^{3}$

Em consequência de tal conflito, tem-se discutido, judicialmente, a possibilidade da dupla proteção, por exemplo, da soja transgênica e quais limites podem ser impostos pelos titulares dos direitos de patentes e de cultivares.

Por isso, faz-se necessário analisar os princípios e limites constitucionais aplicáveis à matéria, a eventual prevalência de um sistema de proteção sobre outro no caso específico, bem como a possibilidade de aplicação simultânea dos dois sistemas de proteção tendo em vista, principalmente as consequências e impactos jurídicos, econômicos e sociais.

$\mathrm{O}$ assunto é relativamente recente no contexto brasileiro, justificando um exame mais detido dos elementos histórico-normativos, dogmáticos e jurisprudenciais, tendo em vista o seu papel no desenvolvimento de novas tecnologias nacionais para a criação de novas variedades vegetais ${ }^{4}$. No entanto, com raras exceções, que serão abordadas, a doutrina pouco avançou sobre o debate da possibilidade de dupla proteção ou no diz que respeito a questão da proteção indireta das novas variedades de plantas. Ademais, se é certo que determinados autores avançaram em debates e conceitos, a análise do tema da possibilidade da dupla proteção das novas variedades vegetais parece ainda mais incipiente junto aos tribunais. Daí a necessidade de dar conta das relações lógiconormativas que advém do sistema complexo de proteção aqui apresentado, o qual combina normas de Propriedade Industrial, Direito da Inovação e Proteção de Novas Cultivares e que impacta diretamente a compreensão sobre as novas cultivares e organismos vivos ou processos patenteados utilizados no desenvolvimento de novas variedades vegetais.

É necessário frisar, ainda, que, diante de um cenário de economia globalizada, em que os conflitos sobre propriedade intelectual podem envolver diversos países nos quais o entendimento sobre a legislação sobre proteção de cultivares se encontra mais sedimentado, carece o Brasil de uma interpretação própria sobre a questão. De outra

\footnotetext{
${ }^{3}$ Acerca do sistema de proteção específico da UPOV, relevante consultar o texto das convenções bem como as notas explicativas constantes de seu sitio web oficial. Disponível em: https://www.upov.int/upovlex/en/upov_convention.html. Acesso em 11 de janeiro de 2019.

${ }^{4}$ Não realizaremos, neste trabalho, análise das políticas públicas de inovação, as quais, tendo em vista sua relevância e singularidade, serão objeto de estudo específico.
} 
forma, o direito pátrio terminará subordinado aos entendimentos alinhados internacionalmente, que nem sempre têm os interesses dos países em desenvolvimento em conta. 


\section{Conclusões}

\section{Impactos e consequências das conclusões preliminares}

Conforme mencionado, nossa preocupação inicial neste trabalho foi dar uma breve notícia histórica acerca da afirmação do sistema de proteção dos direitos dos desenvolvedores de novas variedades vegetais e, nesse aspecto, deparamos com uma primeira questão relacionada à proteção de tais direitos: seria legítimo o patenteamento de seres vivos? $\mathrm{Na}$ análise dos casos submetidos à justiça dos Estados Unidos, verificamos a construção jurisprudencial da Suprema Corte daquele país no sentido de que, salvo vedação expressa na lei de patentes, toda e qualquer criação humana sob o sol, que atendesse aos requisitos para concessão de patente, seria patenteável.

Ademais, também com base na análise de casos judiciais nos Estados Unidos, abordamos quais os princípios de interpretação lá utilizados para definir se o estabelecimento de um sistema específico para proteção de novas variedades vegetais excluiria tais variedades vegetais da proteção pelo sistema de patentes. Nesse sentido, notamos a relevância de se constatar que segundo a Suprema Corte daquele país de que os critérios para afastar a aplicação de determinada legislação seriam: (i) a determinação expressa do legislador de afastar a aplicação de determinado diploma legal; ou (ii) a existência de conflito irreconciliável entre os dois diplomas legais.

Nesse sentido, cumpre ressaltar que houve sempre uma preocupação tanto dos legisladores nacionais, quanto dos organismos internacionais em estabelecer um sistema específico para a proteção dos direitos dos obtentores de novas variedades vegetais. Isso porque, no nosso entendimento, o bem jurídico que se pretende proteger com o sistema de patentes difere do bem jurídico que se pretende proteger com um sistema sui generis para proteção de novas cultivares. De fato, se com o sistema de patentes se pretende proteger precipuamente o investimento e o interesse do inventor, exigindo-se como contrapartida a divulgação do produto e/ou do processo desenvolvido, com o sistema sui generis tem-se não apenas a preocupação com os direitos dos obtentores, mas uma gama de preocupações com a proteção da biodiversidade, com a produção de alimentos e com direitos dos agricultores que não encontram reflexo no sistema de patentes. 
Tal entendimento é embasado com a abordagem da normatividade internacional constante do Capítulo 2 deste trabalho. Com efeito, pode-se constatar que a constituição da UPOV em si mesma parte da preocupação em se proteger o desenvolvimento de novas cultivares e os direitos dos obtentores de modo distinto daquele estabelecido pelo sistema de patentes. De se notar, todavia, que a Convenção UPOV de 1978 estabelecia que caso um estado membro contasse com dois sistemas aplicáveis à proteção de novas variedades vegetais, deveria optar pela aplicação de um único sistema, ao passo que a Convenção UPOV de 1991 foi silente no tocante ao sistema a ser aplicado, o que permite, em tese, o entendimento de que abriu-se a possibilidade de uma combinação de dois sistemas distintos para a proteção de novas cultivares.

Note-se que tal entendimento está consistente com a previsão constante do Artigo 27.3 (b) de TRIPS quando determina que no tocante a variedades vegetais os países membros devem assegurar a proteção de novas variedades vegetais pelo sistema de patentes, por um sistema sui generis ou pela combinação de ambos.

No segundo capítulo analisamos também a legislação específica brasileira com o propósito de constatar que os textos legais da Lei de Propriedade Industrial e da Lei de Proteção das Cultivares poderiam em princípio ensejar entendimento de que novas variedades vegetais obtidas por processos patenteados, poderiam contar também com dupla proteção, seja pelo sistema de patentes, seja pelo sistema de cultivares. Isso porque o Brasil, tendo aderido ao TRIPS, estabeleceu na Lei de Propriedade Industrial que não são patenteáveis o todo ou parte de seres vivos, exceto microrganismos transgênicos, bem como processos não essencialmente biológicos. Isso em princípio, possibilita que um processo patenteável que resulte numa nova variedade vegetal, possa assegurar ao inventor a proteção do produto resultante do processo (a nova variedade vegetal e seu material de reprodução) pelo sistema de patentes, ao passo que a Lei de Proteção de Cultivares prevê (em linha com o disposto na Convenção UPOV 1978) a proteção de novas variedades vegetais exclusivamente de acordo com a Lei de Proteção de Cultivares,

A confirmar a possibilidade de sobreposição e de questionamentos acerca do sistema aplicável à proteção de novas variedades vegetais, analisamos não apenas o caso paradigmático abordado no capítulo terceiro, como, no capítulo 4, a doutrina europeia e brasileira para constatar que também no entendimento da literatura especializada há uma possível sobreposição de direitos previstos no sistema de patentes (e, no caso brasileiro, 
na Lei de Propriedade Industrial) e no sistema sui generis (e, no caso do Brasil, na Lei de Proteção de Cultivares) no tocante às variedades vegetais obtidas mediante processo protegido por patente.

\section{Considerações finais}

Partindo das conclusões preliminares mencionadas acima, a sobreposição de proteção de novas cultivares obtidas por processos patenteados é questão real e altamente controversa, debatida não apenas pela doutrina especializada, mas também pelos tribunais e que justificou o esforço empreendido neste trabalho, no sentido de buscar um entendimento sobre a legislação aplicável à hipótese, bem como eventual solução para a controvertida questão.

É pertinente primeiro analisar as disposições dos tratados internacionais relativos à matéria aos quais o Brasil aderiu, mais especificamente TRIPS e Convenção UPOV 1978 para extrair de referidos tratados a premissa básica de nosso entendimento, qual seja, a de que a intenção dos tratados é assegurar a proteção dos direitos dos obtentores de novas variedades vegetais, sem excluir a possibilidade de se optar pela adoção de um sistema sui generis para tanto. Tanto é assim que TRIPs estabelece expressamente a possibilidade de proteção por sistema de patentes, por sistema específico ou por uma combinação de ambos.

Havendo a possibilidade de proteção por sistema de patentes, aqueles estados que optaram por não o fazer, adotando um sistema específico nos moldes das convenções da UPOV tiveram a preocupação de resguardar bens jurídicos específicos e de forma distinta do que se propõe o sistema de patentes. É o caso do Brasil, que tendo aderido ao TRIPS, promulgou a Lei de Propriedade Industrial, bem como a Lei de Proteção de Cultivares, consistente com a Convenção UPOV 1978, mesmo tendo aderido a tal convenção somente em data posterior.

Importante retomar agora os conceitos e definições constantes da Lei de Propriedade Industrial e da Lei de Proteção de Cultivares para verificar se a sobreposição de proteção constatada representa, de fato um conflito insuperável a ponto de se ter de optar pela aplicação de um único sistema de proteção e pelo afastamento de outro. 
Dispõe a Lei de Propriedade Industrial que não se considerará invenção:

a) o todo ou parte de seres vivos naturais e materiais biológicos encontrados na natureza ou ainda que dela isolados (ou seja, ainda que obtidos por processo não natural),

b) o genoma ou germoplasma de qualquer ser vivo natural, e

c) os processos biológicos naturais.

Estabelece ainda a Lei de Propriedade Industrial que não serão patenteáveis o todo ou parte dos seres vivos (ou seja, ainda que não encontráveis na natureza e possam ser considerados inventos, não serão protegidos por patente), exceto microrganismos transgênicos. E define microrganismos transgênicos como "organismos, exceto o todo ou parte de plantas e animais, que expressem, mediante intervenção humana direta em sua composição genética, uma característica normalmente não alcançável em condições naturais. Aqui cabe ressaltar que foi novamente feita a exceção ao todo ou parte de plantas e animais, a indicar que a patente concedida ao microrganismo transgênico não alcançaria o todo ou parte de plantas e animais.

Mas as exceções e exclusões acima não abordam a questão dos processos não biológicos passíveis de proteção por patente e que possam resultar na obtenção de seres vivos ou materiais biológicos, incluindo variedades vegetais. Estariam os produtos resultantes de referidos processos protegidos pelo disposto no Artigo 42 da Lei de Propriedade Industrial que garante ao titular da patente o direito de impedir terceiros de produzir, usar e comercializar o produto obtido diretamente por processo patenteado?

Propomos responder à questão partindo da análise dos tratados internacionais aos quais o Brasil aderiu e que tratam da matéria. O TRIPS em seu Artigo 27.3. (b) estabelece que:

3. Os Membros também podem considerar como não patenteáveis:

a) métodos diagnósticos, terapêuticos e cirúrgicos para o tratamento de seres humanos ou de animais;

b) plantas e animais, exceto microorganismos e processos essencialmente biológicos para a produção de plantas ou animais, excetuando-se os processos não-biológicos e microbiológicos. Não obstante, os Membros concederão proteção a variedades vegetais, seja por meio de patentes, seja por meio de um sistema sui generis eficaz, seja por uma combinação de ambos. O disposto neste subparágrafo será revisto quatro anos após a entrada em vigor do Acordo Constitutivo da OMC. 
Pela análise do disposto no artigo supratranscrito, vemos que há uma questão redacional importante a ser atacada. O texto na verdade abre a possibilidade de se considerar não patenteáveis:
a) plantas e animais (exceto microrganismos), e
b) processos essencialmente biológicos para produção de plantas e animais (exceto processos não-biológicos e microbiológicos).

É importante levar em consideração a previsão de proteção de variedades vegetais pela combinação de dois sistemas distintos: o sistema de patentes e um sistema sui generis, pois isso, em princípio, conflita com o disposto na Convenção UPOV 1978, à qual o Brasil aderiu em 1999.

Contudo, resta claro que, com a promulgação da Lei de Propriedade Industrial o Brasil optou por legislação consistente com o disposto no Artigo 27.3 (b) do TRIPS para considerar excluídos do que possa ser considerado invenção o todo ou parte de seres vivos naturais e materiais biológicos encontrados na natureza, bem como os processos biológicos.

Reforçou a exclusão ao estabelecer como não patenteáveis os inventos que constituam o todo ou parte de seres vivos (exceto microrganismos transgênicos que não sejam o todo ou parte de plantas e animais).

A Convenção UPOV 1978 em seu Artigo 2, estabelece que:

Artigo 2

Formas de proteção

1. Cada Estado da União pode reconhecer o direito do obtentor previsto pela presente Convenção, mediante a outorga de um título especial de proteção ou de uma patente. Porém, um Estado da União, cuja legislação nacional admite a proteção em ambas as formas, deverá aplicar apenas uma delas a um mesmo gênero ou a uma mesma espécie botânica.

O disposto no Artigo 2 da Convenção UPOV 1978 em princípio, exclui a possibilidade de combinação e dois sistemas distintos para proteção de variedades vegetais ao impor a aplicação de apenas um dos sistemas para proteção de um mesmo gênero ou espécie botânica. 
Novamente, ao promulgar sua legislação específica para proteção de cultivares em 1997, posteriormente à promulgação da Lei de Propriedade Industrial, o Brasil o fez de forma a atender o disposto no tratado internacional que trata especificamente da matéria, a Convenção UPOV 1978 (embora, como já dito, só tenha aderido a tal tratado dois anos depois da promulgação da Lei de Proteção de Cultivares. E a Lei de Proteção de Cultivares estabelece, em consonância com a Convenção UPOV 1978 que:

\begin{abstract}
Art. $2^{\circ} \mathrm{A}$ proteção dos direitos relativos à propriedade intelectual referente a cultivar se efetua mediante a concessão de Certificado de Proteção de Cultivar, considerado bem móvel para todos os efeitos legais e única forma de proteção de cultivares e de direito que poderá obstar a livre utilização de plantas ou de suas partes de reprodução ou de multiplicação vegetativa, no País.
\end{abstract}

Visto que tanto nos tratados internacionais que tratam da matéria, quanto na legislação nacional aplicável existe a possibilidade de sobreposição de proteção de propriedade intelectual para plantas obtidas a partir de processos patenteados ou patenteáveis, parece necessário analisar qual a exata extensão da proteção possível por cada um dos sistemas.

Se atentarmos para o disposto na Lei de Proteção de Cultivares, nos parece claro que a única forma de proteção e forma de direito que poderá obstar a livre utilização de plantas ou suas partes de reprodução é o certificado de proteção de cultivar. Nesse tocante, compactuamos com as lições de SILVEIRA ${ }^{143}$.

Mas tal entendimento deve ser tomado não como afastando o direito de proteção, pelo sistema de patentes, de processos que visem à obtenção de plantas, mas como limitador daquela proteção. Em outras palavras, no tocante aos direitos conferidos ao titular de patente de processo para obtenção de variedades vegetais, a interpretação lógica da legislação brasileira deve ser no sentido de que, para tais patentes (aquelas de produto ou processo que consistam ou resultem em variedades vegetais) os direitos concedidos sejam aqueles previstos na Lei de Proteção de Cultivares.

Tal entendimento contempla uma interpretação que leva em conta não apenas que cada um dos sistemas (de patentes e de proteção de cultivares) pretende proteger bens jurídicos distintos e de formas distintas, mas também leva em conta a estrutura dos

${ }^{143}$ SILVEIRA, Newton. Propriedade intelectual. Manole: Barueri, 5. ed. rev. e ampl, 2014, p. 91. 
tratados internacionais na medida em atende ao disposto em TRIPS e na Convenção UPOV 1978. Mesmo que se leve em conta que a Convenção UPOV 1991 não prevê a obrigatoriedade de aplicação de apenas um sistema, tal interpretação continuaria válida, na medida em que TRIPS abre a possibilidade de uma combinação de dois sistemas para proteção de variedades vegetais.

Na esfera da legislação nacional aplicável à matéria, tal interpretação se sustentaria não apenas no fato de que a intenção do legislador foi clara ao excluir do sistema de patentes o todo ou parte de plantas e animais (excluindo-os do que pode ser considerado invenção, bem como do que possa ser considerado patenteável), mas também no fato de que da Lei de Proteção de Cultivares, atendendo ao disposto na Convenção UPOV 1978, à qual o Brasil aderiu, estabelece que a única forma de proteção de plantas ou de suas partes de reprodução dar-se-á de conformidade com a legislação específica.

Isso não impedirá que se conceda patente de processo para obtenção de variedades vegetais, mas implica que os direitos resultantes de tal patente sejam aqueles previstos na Lei de Proteção de Cultivares, com todas as exigências e restrições inerentes a esse sistema. 


\section{Bibliografia}

ALVES, Maria C. Ferraz. Regulamentação Internacional dos Transgênicos: Contradições e Perspectivas. 330 p. 2009. Tese (Doutorado). Faculdade de Direito da USP, São Paulo, 2009.

ARAÚJO, José Cordeiro. A Lei de Proteção de Cultivares: análise de sua formulação e conteúdo. Brasília: Câmara dos Deputados, Edições Câmara, 2010.

ASSUNÇÃO, Eduardo. Nota sobre patentes e biotecnologia. Disponível em: $<$ http://www.egov.ufsc.br/portal/conteudo/nota-sobre-patentes-e-biotecnologia $>$. Acesso em 10 de janeiro de 2019.

AVIANI, Daniela de Moraes; HIDALGO, José Antônio Fernandes (coord.). Proteção de Cultivares no Brasil. Ministério da Agricultura, Pecuária e Abastecimento. Brasília: Mapa/ACS, 2011. Disponível em: <http:/www.agricultura.gov.br/assuntos/insumosagropecuarios/insumos-agricolas/protecao-de-cultivar/publicacoes/livro-protecaocultivares>. Acesso em 15 de janeiro de 2019.

BARBOSA, Denis Borges. Sobre a propriedade intelectual. Disponível em $<$ http://denisbarbosa.addr.com/arquivos/livros/sobre propriedade intelectual.pdf $>$. Acesso em 07 de novembro de 2018.

Disponível . Proposta para regular a intercessão entre patentes/cultivares, 2010. $<$ http://www.denisbarbosa.addr.com/arquivos/200/economia/patente cultivar.pdf $>$. em: Acesso em 07 de novembro de 2018

. Dois estudos sobre os aspectos jurídicos do patenteamento da tecnologia roundup ready no Brasil - a questão da soja transgênica. 2013. Disponível em: $<$ http://www.denisbarbosa.addr.com/paginas/novidades/novidades.html $>$. Acesso em 12 de novembro de 2018.

. Biotecnologia e Propriedade Intelectual. 2002. Disponível em: $<$ http://www.denisbarbosa.addr.com/arquivos/200/propriedade/80.doc $>$. Acesso em 10 de janeiro de 2019.

. Tratado da propriedade intelectual. Rio de Janeiro: Lumen Juris, 2010.

BARBOSA, Denis Borges; GRAU-KUNTZ, Karin. Exclusions from Patentable Subject Matter and Exceptions and Limitations to the Rights - Biotechnology. 2010. Disponível $\mathrm{em}: \quad<$ http://www.wipo.int/edocs/mdocs/scp/en/scp 15/scp 15 3-annex3.pdf $>$. Acesso em 12 de novembro de 2018 .

BARBOSA, Denis Borges et Al. Intellectual Property and Standards in Brazil A study prepared on support of the "American Academy of Sciences" study on IP Management 
and Standard-Setting Processes. Disponível em: < http://sites.nationalacademies.org/cs/groups/pgasite/documents/webpage/pga_072297.p df>. Acesso em 10 de janeiro de 2010.

BARROS, Carla Eugenia Caldas. A sobreposição dos direitos de propriedade intelectual em biotecnologia: patentes e cultivares. Modificações dos arts. 43 e 70 da Lei 9.279, de 14 de maio de 1996 in PLAZA, Charlene; NERO, Patrícia. Proteção jurídica para as ciências da vida: Propriedade intelectual e biotecnologia. São Paulo: IBPI, 2012.

BASSO, MARISTELA. O direito internacional da propriedade intelectual. Porto Alegre: Livraria do Advogado, 2000.

BASSO, Maristela, POLIDO, Fabrício, BEAS RODRIGUES JUNIOR, Edson (organizadores). Propriedade Intelectual: legislação e tratados internacionais. São Paulo: Atlas, 2007.

BERTOGNA, Viviane A. Biodiversidade e Propriedade Intelectual no Brasil. 2003. Dissertação (Mestrado). Faculdade de Direito da Universidade de São Paulo. São Paulo, 2003.

BOUCHARD, Ron A. Balancing Public and Private Interests in Commercialization of Publicly Founded Biomedical Technologies: Is There a Role for Compulsory Government Royalty Fees? 2007. Disponível em: $<$ https://www.bu.edu/jostl/files/2015/02/Bouchard_132.pdf $>$. Acesso em 15 de janeiro de 2019.

BRUCH, Kelly Lissandra; DEWES, Homero; VIEIRA, Adriana Carvalho Pinto. Proteção de Cultivares e Patentes de Invenção: Uma Coexistência Possível in PIDCC, Aracaju, Ano IV, Volume 09, nº 03, pp. 067-093, Out/2015.

CARVALHO, Sergio Medeiros Paulino de. Proteção de Cultivares no Contexto de Outros Mecanismos de Apropriabilidade: Possíveis Impactos no Mercado Brasileiro de Sementes. 1996. Dissertação (Mestrado) Unicamp, Campinas, 1996.

CASTRO, Luiz Antonio Barreto De. Conditions for the Development of Agricultural Biotechnology in Brazil - National and International Context, Biosafety and Legal Aspects of Intellectual Property Rights. Disponível em: $<$ https://www.upov.int/export/sites/upov/meetings/en/Symposium2002/pdf/wipoupov_sym 02 6_corr.pdf>. Acesso em 15 de janeiro de 2019.

CASABONA, Carlos María Romeo; QUEIROZ, Juliane Fernandes (Coord.). Biotecnologia e suas implicações ético-jurídicas. Belo Horizonte: Del Rey, 2004.

CAVALCANTE. Fernando Castro Silva. Uma Alternativa para o Fortalecimento da Inovação nas Áreas Farmacêutica e de Biotecnologia no Brasil. 2009. 33 p. Dissertação (Mestrado) Programa de Pós-Graduação Interunidades em Biotecnologia USP/ Instituto Butantan/IPT. São Paulo, 2009. 
CERQUEIRA, João da Gama. Tratado da Propriedade industrial. São Paulo: RT, 1982, 2 volumes.

CHAMAS, Cláudia Inês. Propriedade Intelectual e Genômica in IACOMINI, Vanessa (Coord.). Propriedade intelectual e biotecnologia. Curitiba: Juruá Editora, 2009. pp. 7192.

CORREA, C. M. Biodiversidade, Propriedade Intelectual e Comércio Internacional in

Revista CEJ, V. 3 n. 8 mai./ago. 1999. Disponível em: $<$ http://www.jf.jus.br/ojs2/index.php/revcej/article/view/205/367>. Acesso em 1211 de janeiro de 2019.

DAL POZ, Maria Ester; BARBOSA, Denis Borges. Incertezas e riscos no patenteamento de biotecnologias: a situação brasileira corrente in IACOMINI, Vanessa (Coord.). Propriedade intelectual e biotecnologia. Curitiba: Juruá Editora, 2009. pp. 93-138.

DANNEMANN, Siemsen, Bigler \& Ipanema Moreira. Comentários à Lei da propriedade industrial e correlatos. Rio de Janeiro: Renovar, 2001.

DEL NERO, Patrícia Aurélia, ÁVILA PLAZA, Charlene Maria C. Proteção Jurídica para as Ciências da Vida: Propriedade Intelectual e Biotecnologia. São Paulo: IBPI. 2012.

DEL NERO, Patrícia Aurélia, Propriedade Intelectual: A tutela jurídica da biotecnologia, 2. ed. São Paulo: Revista dos Tribunais, 2004.

. Biotecnologia: análise crítica do marco jurídico regulatório. São Paulo: Ed. Revista dos Tribunais, 2008.

A proteção ambiental da Biotecnologia in IACOMINI, Vanessa (Coord.). Propriedade intelectual e biotecnologia. Curitiba: Juruá Editora, 2009. pp. 139-162.

DI BIASI, Gabriel. Fatores ambientais de propriedade industrial para investimentos em biotecnologia na America Latina in Revista da ABPI, Rio de Janeiro: n. 39, p. 32-36, mar/abr, 1999.

DIAS DE SÁ, Camila. Propriedade Intelectual na Cadeia de Flores e Plantas Ornamentais: Uma Análise da Legislação Brasileira de Proteção de Cultivares. 2010. Dissertação (Mestrado) Departamento de Administração da FEA/USP, São Paulo, 2010.

EPO. Biotechnology Comparative Study on Biotechnology Patent Practices of the European Patent office, the Japanese Patent Office and the US Patent and Trademark Office. Disponível em: http://www.epo.co.at/tws/sr-3-bio.htm.

FERRAZ Jr., Tércio Sampaio. Propriedade industrial e defesa da concorrência in Revista da ABPI, São Paulo, Anais do XIII Seminário Nacional de Propriedade Industrial, 1993, p. 10-12. 
FURTADO, Lucas Rocha. Sistema de propriedade industrial no direito brasileiro. Brasília: Editora Brasília Jurídica, 1996.

FERRAZ JUNIOR, Tercio Sampaio. Introdução ao estudo do direito: técnica, decisão, dominação. São Paulo: Atlas, 2016.

FERRERO ZOCCOLATO, Graziela, FREITAS, Rogério Edvaldo, Propriedade Intelectual e Aspectos Regulatórios em Biotecnologia, Brasília: IPEA, 2013.

FRANCISCO, Alison Cleber. Royalties de Cultivares Transgênicas: sua Formação no Plano Nacional e Internacional sob a Convenção da UPOV. 2009. Dissertação (Mestrado) Faculdade de Direito da Universidade de São Paulo, São Paulo, 2009.

FREIRE, Carlos Eduardo Torres, Biotecnologia no Brasil: uma atividade econômica baseada em empresa, academia e Estado. Tese (doutorado) Programa de Pós-Graduação em Sociologia, orientador Glauco A. T. Arbix. São Paulo, 2014.

GARCIA, Balmes Veja. Direito e Tecnologia: Regime Jurídico da Ciência, Tecnologia e Inovação. São Paulo: Editora LTr, 2008.

GARCIA, Selemara Berckembrock Ferreira. A proteção jurídica das cultivares no Brasil. Curitiba: Juruá, 2004.

GONTIJO, Cícero Ivan Ferreira Gontijo. As Transformações do Sistema de Patentes, da Convenção de Paris ao Acordo Trips in BARBOSA, Denis Borges (Org.). Direito Internacional da Propriedade Intelectual, Rio de Janeiro: Lumen Juris, 2008. pp. 193-218.

GRACIANO, Lilian Lúcia. Biotecnologia e o Futuro da Sociedade in IACOMINI, Vanessa (Coord.). Propriedade intelectual e biotecnologia. Curitiba: Juruá Editora, 2009. pp. 203-215.

GREENGRASS, B. Direito de obtentores e outras formas de proteção de propriedade intelectual. Simpósio sobre propriedade intelectual na agricultura e proteção de cultivares in Anais COBRAFI, 1993. p. 29-46.

IACOMINI, Vanessa. Os Direitos de Propriedade Intelectual e a Biotecnologia in IACOMINI, Vanessa (Coord.). Propriedade intelectual e biotecnologia. Curitiba: Juruá Editora, 2009. pp. 13-30.

INPI, Diretrizes de Exame do INPI (outras áreas). Disponível em: $<$ http://www.inpi.gov.br/menu-servicos/patente/consultaspublicas/arquivos/diretriz de exame de patente retificado_original 1.pdf $>$._Acesso em 15 de janeiro de 2019.

KAGEYAMA, A. Coord. Biotecnologia e propriedade intelectual: novas cultivares. Brasilia: IPEA, 1993. 
LEONARDOS, Gustavo Starling. Da data de aplicação no Brasil do acordo sobre aspectos dos direitos de propriedade intelectual relacionados ao comércio. TRIPS in Revista da ABPI, nº 17, edição especial, TRIPS, SP. jul/agosto, 1995. p. 6-12.

MAGALHÃES, Vladimir Garcia. Propriedade intelectual: biotecnologia e biodiversidade. São Paulo: Editora Fiuza, 2011.

MIRANDA, F. C. Pontes de. Tratado de Direito Privado: Parte Especial. Tomo XVII. São Paulo: RT, 1983, $4^{\mathrm{a}}$ ed.

MOLINA-PALMA, Manuel Antonio. A capacidade de inovação como formadora de valor: análise dos vetores de valor em empresas brasileiras de biotecnologia. Tese (Doutorado), Faculdade de Economia, Administração e Contabilidade da Universidade de São Paulo, 2004.

MONTEIRO, Guilherme Fowler de Ávila Monteiro. Direitos de Propriedade, Estratégia e Ambiente Institucional. Programa de Pós-Graduação em Administração da Faculdade de Economia, Administração e Contabilidade da Universidade de São Paulo. São Paulo, 2010 .

MORAES, Marcelo Gravina de. A Legalidade da Proteção por Cultivares de Plantas na Propriedade Intelectual e da Biotecnologia com Cobrança de Royalties via Patente in Revista da ABPI, Rio de Janeiro: n. 135, mar/abr, 2015. p. 3-5.

MILL, John Stuart. Utilitarismo. Porto: Porto Editora, 2005.

NAVES, Bruno Torquato de Oliveira; FREIRE DE SÁ, Maria de Fátima. A Patenteabilidade das Descobertas Genéticas: Estudo sobre o Impacto do Projeto Genoma Humano sobre o Direito das Patentes in IACOMINI, Vanessa (Coord.). Propriedade intelectual e biotecnologia. Curitiba: Juruá Editora, 2009. pp. 63-70.

OCTAVIANI, Alessandro. Recursos Genéticos e Desenvolvimento, 2008. Faculdade de Direito da Universidade de São Paulo. ORLANS, F. Barbara et Al., The Human Use of Animals: Case Studies in Ethical Choice. Nova Iorque, Oxford University Press, 1998.

ORLANS, F. Barbara et Al. The Human Use of Animals: Case Studies in Ethical Choice, Nova Iorque, Oxford University Press, 1998.

PATERNIANI. E. Melhoramento convencional e transgenia: o que mudou in Jornal da ANBio. Ano I, n. 1, jan/2001.

PLAZA, Charlene de Ávila. Das patentes aos royalties - O caso da soja transgênica da Monsanto in PIDCC, Aracaju, Ano II, Edição no 03/2013, Jun/2013. p. 01-40.

- Notas sobre patentes e certificados de cultivares: conflitos ou complementos de proteção? in Revista da ABPI, n. 118, mai/jun de 2012. 
. Interface dos direitos protetivos em propriedade intelectual: patentes e cultivares. Revista da ABPI, n. 112, mai/jun. 2011.

. As especificidades das patentes do material genético de plantas in PIDCC, Aracaju, Ano III, Edição nº 06/2014Jun/2014. pp. 387-424.

PLAZA, Charlene de Ávila; SANTOS, Nivaldo dos. Interpenetração de direitos de proteção em propriedade intelectual: o caso das patentes de invenção e cultivares in Anais do XIX Encontro Nacional do CONPEDI, Fortaleza, 2010.

POLIDO, Fabrício Bertini Pasquot. Contribuições ao Estudo do Direito Internacional da Propriedade Intelectual na Era Pós-Organização Mundial do Comércio: Fronteiras da Proteção, Composição do Equilíbrio e Expansão do Domínio Público. 2010. Tese (Doutorado) Faculdade de Direito da Universidade de São Paulo, São Paulo, 2010.

PONTES DE MIRANDA. Tratado de Direito Privado. Direito das Coisas. Rio de Janeiro: Editor Borsoi, 1956.

PORTO, Patrícia C. R. Limites à sobreposição de direitos de propriedade intelectual. in Revista da ABPI, Nov/dez, 2010, n. 109.

REALE, Miguel. Aplicação da Convenção de Paris no Brasil in Revista da ABPI - Anais do II Seminário Nacional de Propriedade Industrial, 1982. p. 17-23.

REMÉDIO MARQUES, J.P. Biotecnologia(s) e Propriedade Intelectual (Volumes I e II). Lisboa: Editora Almedina, 2007.

RODRIGUES, Roberta L., LAGE, Celso L.S. and VASCONCELLOS, Alexandre G. Intellectual property rights related to the genetically modified glyphosate tolerant soybeans in Brazil in Anais da Academia Brasileira de Ciências, 2011.

SALLES, Marcus Maurer de. A Biotecnologia Agrícola sob a Ótica do Desenvolvimento in IACOMINI, Vanessa (Coord.). Propriedade intelectual e biotecnologia. Curitiba: Juruá Editora, 2009. pp. 31-44.

SAN EPIFANIO, Leire Escajedo. Avanços biotecnológicos e meio ambiente: implicações éticas e jurídicas da Biossegurança in CASABONA, Carlos María Romeo; QUEIROZ, Juliane Fernandes (Coord.). Biotecnologia e suas implicações ético-jurídicas. Belo Horizonte: Del Rey, 2004. pp. 377-430.

SANTOS, Manoel J. Pereira dos; JABUR, Wilson Pinheiro (Coord.) Propriedade Intelectual: contratos de propriedade industrial e novas tecnologias. São Paulo: Saraiva, 2007.

SCHOLZE, S. H. C. A propriedade intelectual e a biotecnologia: aspectos jurídicos e éticos do controle técnico da vida. 1997. Dissertação (Mestrado). Faculdade de Direito da UnB, 1997. 
SILVEIRA, Newton e FRANCISCO, Alison. A UPOV 1991 e um Novo Marco Regulatório para as Cultivares no Brasil in Revista Eletrônica do IBPI., jul/2010, n.2.

SILVEIRA, Newton. A propriedade intelectual e as novas leis autorais. Saraiva: São Paulo, 2. ed. rev. e ampl, 1998.

. Propriedade intelectual. Manole: Barueri, 5. ed. rev. e ampl, 2014.

SIMON, Jürgen. Biotecnologia e Lei de Patentes sob perspectiva europeia in CASABONA, Carlos María Romeo; QUEIROZ, Juliane Fernandes (Coord.). Biotecnologia e suas implicações ético-jurídicas. Belo Horizonte: Del Rey, 2004. pp. 470484.

THEODORO JÚNIOR, Humberto. Curso de Direito Processual Civil Vol. III. Rio de Janeiro: Forense, 2016.

TOLEDO, Simone Seghese de. Transgênicos e a nova lei de biossegurança in SOUZA, Vinicius Roberto Prioli de (Coord.). Propriedade Intelectual: alguns aspectos da propriedade industrial e da biotecnologia. Curitiba: Juruá Editora, 2011, pp. 83-99.

URANGA, Amelia Martín. As invenções biotecnológicas à vista das Decisões do Departamento Europeu de Patentes e do Tribunal de Justiça das Comunidades Europeias in CASABONA, Carlos María Romeo; QUEIROZ, Juliane Fernandes (Coord.). Biotecnologia e suas implicações ético-jurídicas. Belo Horizonte: Del Rey, 2004. pp. 431470.

VIEGAS, Juliana L. B. Dos contratos de transferência de tecnologia sob o regime da nova lei de propriedade industrial in Revista da ABPI, n 34, maio/junho, 1998. p. 24-31.

VIVANT, Michael (org.). Les créations immatérielles et le droit. Paris: Ellipses, 1997.

WOLFF, Maria Thereza Mendonça, Biotecnologia, seu patenteamento e a biossegurança in Revista da ABPI, no. 12 jul./out., 1994. p. 108-110.

ZILBERSZTAJN, Decio. Qual o preço das sementes? in Jornal o Estado de São Paulo, Caderno de economia, 2 de março de 2013. Disponível em: $<$ https://economia.estadao.com.br/noticias/geral,qual-o-preco-das-sementes-imp,1003460>. Acesso em 15 de janeiro de 2019. 